\title{
Laccase-conjugated amino-functionalized nanosilica for efficient degradation of Reactive Violet 1 dye
}

\author{
Mayur Gahlout $^{1} \cdot$ Darshan M. Rudakiya $^{1} \cdot$ Shilpa Gupte $^{2} \cdot$ Akshaya Gupte $^{1}$
}

Received: 12 October 2016/Accepted: 4 August 2017/Published online: 8 August 2017

(C) The Author(s) 2017. This article is an open access publication

\begin{abstract}
Immobilization of enzyme with nanostructures enhances its ideal characteristics, which may allow the enzyme to become more stable and resistant. The present investigation deals with the formulation of laccase nanosilica conjugates to overcome the problems associated with its stability and reusability. Synthesized nanosilica and laccase nanoparticles were spherical shaped, with the mean size of 220 and $615 \mathrm{~nm}$, respectively. Laccase nanoparticles had an optimum temperature of $55^{\circ} \mathrm{C}$ and $\mathrm{pH} 4.0$ for the oxidation of ABTS. Laccase nanoparticle retained $79 \%$ of residual activity till 20th cycle. It also
\end{abstract}

showed $91 \%$ of its initial activity at lower temperatures even after 60 days. Laccase nanoparticles were applied for Reactive Violet 1 degradation wherein $96.76 \%$ of decolourization was obtained at $\mathrm{pH} 5.0$ and $30{ }^{\circ} \mathrm{C}$ within $12 \mathrm{~h}$. Toxicity studies on microbes and plants suggested that the degraded metabolites were less toxic than control dye. Thus, the method applied for immobilization increased storage stability and reusability of laccase, and therefore, it can be utilized for efficient degradation of azo dyes.

Akshaya Gupte

akshaya_gupte@hotmail.com

1 Department of Microbiology, Natubhai V. Patel College of

Pure and Applied Sciences, Vallabh Vidyanagar, Anand,

Gujarat 388 120, India

2 Ashok and Rita Patel Institute of Integrated Study and

Research in Biotechnology and Allied Sciences, New

Vallabh Vidyanagar, Anand, Gujarat 388 121, India 


\section{Graphical Abstract}

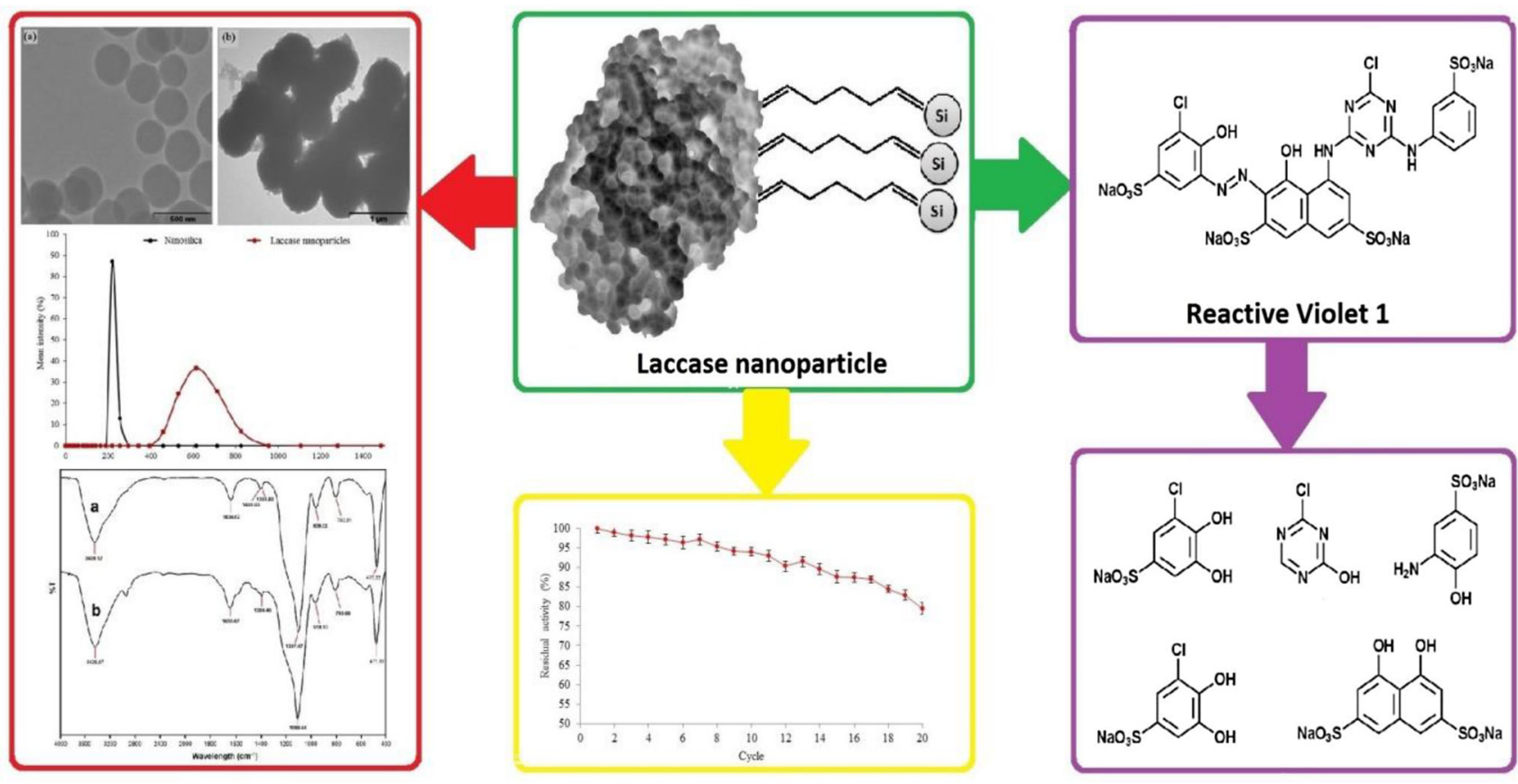

Keywords Biocatalyst - Ganoderma cupreum AG-1 . Laccase nanoparticle $\cdot$ Nano-immobilization $\cdot$ Reactive Violet 1

\section{Introduction}

Enzymes catalyse more specific reactions inside living systems under mild conditions; therefore, they are efficient alternate for chemical catalysts [1]. The economy of biocatalytic process can be improved by enzyme reusability and stability by means of immobilization [2, 3]. The challenges of using immobilized enzymes are identifying new matrix materials with appropriate structural characteristics, such as morphology and surface functionality [4].

Recently, carbon nanotubes, nanosized polymer beads, and metal nanoparticles are utilized as immobilization matrices of enzymes [5]. The use of nanomaterials not only offers advantages such as large surface area, increased mechanical strength, and effective enzyme loading, but also exhibits high catalytic efficiency [6, 7]. Enzyme nanoimmobilization can be performed by either physical or chemical modification. Although physical nano-immobilization leads to weaker interaction with enzymes, conformation of the enzyme is unaffected. Chemical nanoimmobilization method changes the enzyme conformation, but it provides the strong covalent bond formation. 3-Aminopropyltriethoxisaline (APTES) is the aldehyde anchoring chemical, which is subsequently attached and formed covalent bond. This modification provides strong cross-linking with protein amino surface with nanoparticles. The catalytic efficiency of an enzyme decreases due to the steric effects, limited freedom of active site, and diffusion barriers when enzyme conjugated with nanostructures $[8,9]$. In addition, the binding affinity of peroxidase was decreased by immobilizing it on graphene (graphane) oxide by electrostatic interactions [8]. However, the effect of nanomaterials, substrate acted on enzyme activity, and interface nature between enzyme and nanomaterials has not been fully elucidated [10].

Laccases (E.C. 1.10.3.2) catalyse the removal of hydrogen atom from hydroxyl group of $o$ - and $p$ - substituted mono-phenolic and poly-phenolic substrates and from aromatic amines by one electron abstraction to form free radicals as well as capable of further reaction such as depolymerisation, re-polymerization, demethylation, or quinone formation [11, 12]. Immobilized laccase has a wide range of commercial applications such as formulation of biosensors and biofuel cells, toxic pollutant degradation, and transformation of industrially and medicinally important compounds [4, 13-15]. Laccases have been successfully immobilized with nanomaterials such as nanoparticles, nano-composite, carbon nanotubes, and nanogels [16-18].

Laccase nano-immobilization is a promising strategy for recovering laccase on amino-functionalized nanosilica. The present study is aimed to fabricate and characterize laccase-conjugated amino-functionalized nanosilica. Furthermore, prepared nano-biocatalyst was applied for the degradation of Reactive Violet 1 (RV 1) dye. Based on 
several analytical procedures such as UV-visible spectrophotometry, HPTLC, and GC-MS/MS analysis, we demonstrated the produced nano-biocatalyst was efficient for decolourizing and degrading RV 1 dye. Toxicity assessment of RV 1 dye and degraded metabolites were also evaluated on microbes and on plants.

\section{Materials and methods}

\section{Chemicals}

2, 2-Azino-bis (3-ethylbenzthiozoline-6-sulphonic acid) (ABTS), tetraethyl orthosilicate (TEOS), APTES, and Sephadex G-75 were purchased from Sigma-Aldrich (St. Louis, USA). Fungal media, agar-agar, and other chemicals were purchased from Hi-media Labs. (Mumbai, India). RV 1 dye was procured from Meghmani Enterprise Pvt. Ltd. (Ahmedabad, India). All other reagents used were of analytical grade with highest purity.

\section{Laccase production and purification}

Solid-state fermentation strategy was used for laccase production using Ganoderma cupreum AG-1. An Erlenmeyer flask containing wheat straw (5 gm) was moistened with Asther's medium to give a final substrate to moisture ratio of 1:4 [19]. Actively grown fungal mycelia (5 agar plugs; $8 \mathrm{~mm}$ diameter) was inoculated on moistened wheat straw and incubated it for 16 days at $30{ }^{\circ} \mathrm{C}$. Extrudates were extracted by squeezing fermented wheat straw using muslin cloth and centrifuged at $8000 \mathrm{rpm}$ and $4{ }^{\circ} \mathrm{C}$ for $15 \mathrm{~min}$. The obtained supernatant was precipitated using ammonium sulfate saturation procedure. Furthermore, precipitated protein was dialyzed overnight in Na-acetate buffer and purified using gel filtration chromatography (Sephadex G-75) at pH 5.0 (Na-acetate buffer, $50 \mathrm{mM})$.

\section{Laccase assay}

Laccase assay was performed by incubating purified laccase $(100 \mu \mathrm{l})$ with ABTS $(1 \mathrm{mM}, 100 \mu \mathrm{l})$ in $800 \mu \mathrm{l}$ of Naacetate buffer $(50 \mathrm{mM}, \mathrm{pH} 5.0)$. The rate of substrate oxidation was monitored for purified and laccase nanoparticle at $420 \mathrm{~nm}(\varepsilon=36,000 \mathrm{~cm} / \mathrm{M})$ in a UV-visible spectrophotometer following the method described by Rudakiya and Gupte [20]. One unit of enzyme activity $(\mathrm{U})$ is defined as the amount of enzyme oxidizes $1 \mu \mathrm{M}$ of ABTS per min.

\section{Laccase nanoparticle preparation}

The nanosilica was chemically synthesized according to the method described by Stöber et al. [21]. Preparation of nanosilica was carried out by mixing TOES $(4 \mathrm{ml})$ and $\mathrm{NH}_{4} \mathrm{OH}(3.3 \mathrm{ml}, 24 \% \mathrm{w} / \mathrm{v})$ in ethanol $(47 \mathrm{ml})$ at $20{ }^{\circ} \mathrm{C}$ for $24 \mathrm{~h}$ with moderate stirring. The resulting suspension was transferred to filtration assembly equipped with cellulose filtration membrane (cut off; $50 \mathrm{kDa}$ ) and washed thoroughly with water. With this suspension, APTES $(300 \mu \mathrm{l})$ was added and reaction was maintained under vigorous stirring for $20 \mathrm{~h}$. Prepared suspension was washed three times with Sorenson's phosphate buffer (pH 7.0) and collected in the pellet form by centrifuging it for $3 \mathrm{~min}$ at $10,000 \mathrm{rpm}$. After washing step, pellet of nanosilica was dried under reduced pressure and produced nanoparticles are called amino-functionalized nanosilica.

Dried amino-functionalized nanosilica $(300 \mathrm{mg}$ ) was incubated with glutaraldehyde solution $(250 \mu \mathrm{l}, 50 \% \mathrm{v} / \mathrm{v})$ in Sorenson's phosphate buffer $(40 \mathrm{mM}, \mathrm{pH} 7.0)$ under stirring condition. Glutaraldehyde-activated nanosilica (100 mg) was washed twice with the same buffer and incubated with different concentration of purified laccase $(100-800 \mu \mathrm{g})$ at $4{ }^{\circ} \mathrm{C}$ for $12 \mathrm{~h}$. Laccase cross-linked amino-functionalized nanosilica was called as laccase nanoparticles. Immobilization yield of laccase nanoparticle for each laccase concentration was calculated by Huang et al. [22], which is defined by the following equation:

$\mathrm{IY} \%=\mathrm{PB} / \mathrm{PU} \times 100$,

where IY is immobilization yield, PU is Protein used for immobilization, and PB is Protein bound to a nanoparticle; the amount of bound proteins were evaluated indirectly by measuring the quantity of protein remaining in washing solution by Lowry's method [23].

\section{Characterization of laccase nanoparticles}

\section{Structural and functional characterization}

Structural elucidation of nanosilica and laccase nanoparticles was acquired using microscopic, spectroscopic, and light scattering techniques. The size and shape of nanosilica and laccase nanoparticles were analysed using transmission electron microscopy (Tecnai 20, Philips, Holland). The interaction of laccase with amino-functionalized nanosilica was studied by Fourier Transform Infrared Spectroscopy (Spectrum GX, Perkin Elmer, USA). The average size of nanosilica and laccase nanoparticles was observed using dynamic light scattering analyzer (Zetasizer S-90, UK). 


\section{Temperature and pH optima}

Temperature optimum was examined by incubating the purified laccase and laccase nanoparticles in Na-acetate buffer $(50 \mathrm{mM}, \mathrm{pH} 5.0)$ at different temperatures $\left(30-70{ }^{\circ} \mathrm{C}\right)$. The $\mathrm{pH}$ optima of purified laccase and laccase nanoparticles were determined by monitoring the oxidation of ABTS in the $\mathrm{pH}$ range from 2.0 to 8.0 at $30^{\circ} \mathrm{C}$. Naacetate $(50 \mathrm{mM}, \mathrm{pH} 3-5)$ and Na-phosphate $(50 \mathrm{mM}, \mathrm{pH}$ 6-8) buffers were used to maintain the $\mathrm{pH}$. Residual activities of purified laccase and laccase nanoparticles were measured after $1 \mathrm{~h}$ of incubation.

\section{Temperature and $\mathrm{pH}$ stability}

Thermal stability of purified laccase and laccase nanoparticles was determined at different temperatures $\left(30-70{ }^{\circ} \mathrm{C}\right)$ in Na-acetate buffer $(50 \mathrm{mM}, \mathrm{pH} 5.0)$ for $24 \mathrm{~h}$. The $\mathrm{pH}$ stability was studied by incubating laccase nanoparticles and purified laccase in Na-acetate buffer at different $\mathrm{pH}$ values $\left(3.0,4.0\right.$, and 5.0) for $24 \mathrm{~h}$ at $30{ }^{\circ} \mathrm{C}$. Residual activities were measured periodically at an interval of $4 \mathrm{~h}$ under standard assay conditions.

\section{Storage stability and reusability}

Purified laccase and laccase nanoparticles were stored at 4 and $-20{ }^{\circ} \mathrm{C}$ and residual activities were measured periodically at an interval of 10 days for 60 days under standard assay conditions. Reusability of laccase nanoparticles (100 mg) was determined by incubating it with ABTS in Na-acetate buffer at $30{ }^{\circ} \mathrm{C}$ for $3 \mathrm{~min}$. Operational stability were carried out for 20 cycles wherein samples were withdrawn after an interval of $3 \mathrm{~min}$ and absorbance was measured at $420 \mathrm{~nm}$. Laccase nanoparticles were collected by centrifuging $(10,000 \mathrm{rpm}, 10 \mathrm{~min})$ and washing twice with Na-acetate buffer. Subsequently, washed laccase nanoparticles were re-suspended in a fresh substrate solution and assayed subsequently.

\section{Kinetic studies of laccase nanoparticle}

The kinetic parameter of purified laccase and laccase nanoparticles was determined at $30{ }^{\circ} \mathrm{C}$ using ABTS (0.05-100 mM) in Na-acetate buffer (50 mM, pH 5.0). Kinetic parameter $K_{\mathrm{m}}$ and $V_{\max }$ were obtained using Line weaver-Burk plots. All assays were performed in triplicates.

\section{RV 1 dye decolourization experiments}

Aqueous solution of RV 1 dye $(1000 \mathrm{mg} / \mathrm{l})$ was mixed in Na-acetate buffer (50 mM, pH 5.0) to give a final concentration of $100 \mathrm{ppm}$ in experimental flask. The reaction was initiated by addition of purified laccase (2000 $\mathrm{U})$ and laccase nanoparticles (2000 U), and mixture was incubated for $12 \mathrm{~h}$ at $30{ }^{\circ} \mathrm{C}$. The samples were withdrawn periodically at an interval of $2 \mathrm{~h}$ and decolourization was analysed spectrophotometrically using UV-visible spectrophotometer. Decolourization of RV 1 was recorded by measuring the absorbance at $560 \mathrm{~nm}$. The $\%$ decolourization was calculated by the following equation:

$\%$ Decolourization $=\left(A_{\mathrm{i}}-A_{\mathrm{o}}\right) / A_{\mathrm{i}} \times 100$,

where $A_{\mathrm{i}}$ and $A_{\mathrm{o}}$ are the initial and observed absorbance of the samples at different time intervals, respectively.

Physic-chemical parameters, i.e., temperature and $\mathrm{pH}$ were monitored to study the effect on decolourization of $\mathrm{RV} 1$. Effect of $\mathrm{pH}$ on $\mathrm{RV} 1$ decolourization was determined by measuring \% decolourization in $2.0-7.0 \mathrm{pH}$ range. The effect of temperature on decolourization of $\mathrm{RV}$ 1 was determined by measuring $\%$ decolourization at different temperature in the range of $20-60{ }^{\circ} \mathrm{C}$.

\section{Analysis of degradation metabolites}

The degraded metabolites were extracted in ethyl acetate, concentrated in a rotary vacuum evaporator, and re-dissolved in a small volume of ethyl acetate. HPTLC analysis was performed to compare the $R_{\mathrm{f}}$ values of RV 1 dye and degraded metabolites on pre-coated silica gel $60 F_{254}$ plate. The chromatogram was observed at $254 \mathrm{~nm}$ using Camag TLC scanner 3. Identification of RV 1 dye and decolourized metabolites was conducted using the GC-MS/MS analysis with $30 \mathrm{~m}$ fused silica column (HP-5 $30 \mathrm{~m} \times 0.53 \mathrm{~mm}$; Agilent Technologies, USA). The temperature of injection port was at $275^{\circ} \mathrm{C}$ and performed at $70 \mathrm{eV}$.

\section{Toxicity analysis of degraded metabolites}

Microbial toxicity assessment of RV 1 (500 mg/l) and degraded metabolites was conducted using micro-organisms like Bacillus subtilis, Streptococcus aureus, Salmonella typhi, Escherichia coli, Rhizobacter radiobacter, and Azotobacter sp. The antibacterial action of RV 1 dye and degraded metabolites was studied using well diffusion method wherein inhibition zone surrounding the well represented the toxicity index. The phytotoxicity assessment of dye (500 and $1000 \mathrm{mg} / \mathrm{l})$ as well as degraded metabolites was carried out on Pennisetum glacum and Vigna radiate [24]. Ten seeds of respective plants were germinated in small pots; daily supplemented with relevant contents (distilled water, dye, or degraded metabolites) to seeds and maintaining light $(12 \mathrm{~h})$ and temperature $\left(30^{\circ} \mathrm{C}\right)$ in a controlled environment. Toxic effects were measured 
in terms of $\%$ germination, plumule length, and radical length of plant after 7 days.

\section{Results and discussion}

\section{Effect of laccase concentration cross-linking with nanosilica}

To introduce primary amino-functions, reaction of TOES and $\mathrm{NH}_{4} \mathrm{OH}$ in ethanolic solution with APTES allows the addition of amino layers on the surface of nanosilica. Glutaraldehyde molecules one side attach with laccase via amine groups of its peripheral lysine residues and amino groups of nanosilica bind on the other side. The protein content was less detected in elute while increasing the concentration of protein from 100 to $400 \mu \mathrm{g} / \mathrm{ml}$. Immobilization yield of laccase nanoparticles was maximum (92\%) when protein $(400 \mu \mathrm{g} / \mathrm{ml})$ was cross-linked with nanosilica. Maximum laccase activity was $824 \mathrm{U} / \mathrm{ml}$ on laccase nanoparticles which is shown in Fig. 1. Lack of additional bound protein with increasing protein amount (above $400 \mu \mathrm{g} / \mathrm{ml}$ ) in the reaction mixture suggested that the surfaces of nanosilica were saturated with protein. This might be due to the formation of a dense protein layer, which caused a stearic hindrance and diffusion barrier for the assessment of the enzyme on the immobilization carrier, resulting in a low immobilization yield. Similar results were reported by Al-Adhami et al. [25] wherein $1 \mathrm{mg} / \mathrm{ml}$ protein was optimum concentration for the immobilization on DEAE-Granocel support. An increase in laccase concentration from 0.25 to $2.0 \mathrm{mg} / \mathrm{ml}$ results in the increased laccase activity for the immobilization with CuTAPc$\mathrm{Fe}_{3} \mathrm{O}_{4}$ composite [21]. Bayramoglu et al. [26] also reported adsorption capacity of CHX-g-p(IA) and CHX-g-p(IA)$\mathrm{Cu}$ (II) membranes for laccase increased as the protein concentration increased from 0.1 to $1.0 \mathrm{mg} / \mathrm{ml}$.

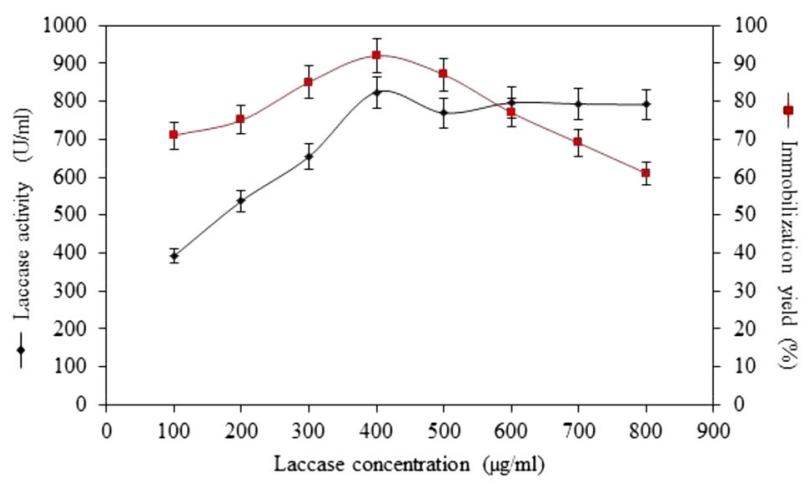

Fig. 1 Effect of laccase protein concentration on the immobilization yield

\section{Characterization of laccase nanoparticle}

The preparation of nanosilica and laccase nanoparticle was confirmed by observing micrographs on transmission electron microscope (Fig. 2a). Nanosilica had a spherical structure with smooth surfaces. It can be observed that laccase was effectively immobilized on amino-functionalized nanosilica due to their larger surface area. Thus, laccase nanoparticles showed the rough spherical surface, which can be shown in Fig. 2b. The DLS of nanosilica and laccase nanoparticles were 220 and $615 \mathrm{~nm}$, respectively (Fig. 2c). The FTIR spectrum of laccase nanoparticles showed peak at 1099, 958, and 796/cm which corresponded to asymmetric vibration of $\mathrm{Si}-\mathrm{O}, \mathrm{Si}-\mathrm{OH}$, and symmetric vibration of $\mathrm{Si}-\mathrm{C}$ in nanosilica and laccase nanoparticles (Fig. 3). The absorption band between 3300 and $3500 \mathrm{~cm}^{-1}$ is assigned to $\mathrm{O}-\mathrm{H}$ stretching and $\mathrm{H}$-bonded water with nanosilica [27]. The absorbance shift of nanosilica that was changed due to the laccase was crosslinked with nanosilica. The FTIR spectrum of laccase nanoparticle showed a peak at 2935/cm for C-H stretching, confirming cross-linking of laccase with nanosilica by glutaraldehyde molecule [28].

\section{Temperature and pH optima}

Residual activity of laccase nanoparticles on different temperature values was determined and compared to the purified laccase. A shift in the optimum temperature towards higher value was observed after cross-linking of laccase on nanosilica. The optimum temperature of purified laccase was found to be $50{ }^{\circ} \mathrm{C}$, while $55^{\circ} \mathrm{C}$ was the optimum temperature for laccase nanoparticle (Fig. 4a). A shift towards the higher value may be attributed due to the use of nanosilica and their interaction with laccase. In contrast, several researchers showed that the optimum temperature was shifted towards lower temperature values [29]. Optimum temperature of free laccase and laccase immobilized $\mathrm{Fe}_{3} \mathrm{O}_{4}$-CS-EDAC nanoparticles was 40 and $30^{\circ} \mathrm{C}$, respectively. Huang et al. also stated that 55 and $45^{\circ} \mathrm{C}$ were optimum temperatures for free and $\mathrm{CuTAPc}-\mathrm{Fe}_{3} \mathrm{O}_{4}$ nanoparticle laccase, respectively [22].

The oxidation reaction for purified laccase and laccase nanoparticles had maximum activity at $\mathrm{pH} 3.0$ and 4.0, respectively (Fig. 4b). Almost $15 \%$ of relative activity was retained at $\mathrm{pH} 8.0$, while purified laccase was inactive. The results showed one unit shift in optimum $\mathrm{pH}$ towards higher value after cross-linking of laccase on nanosilica. This may be attributed due to nanosilica that has been changed micro-environment of laccase, the ionic interaction between enzyme, and charged surfaces of nanosilica. Laccase nanoparticle showed more than 90\% residual activity in $\mathrm{pH}$ range of 3-5, while purified laccase obtained 
Fig. 2 Transmission electron micrographs of a nanosilica, b laccase nanoparticle, and c dynamic light scattering (DLS) analysis of nanosilica and laccase nanoparticle
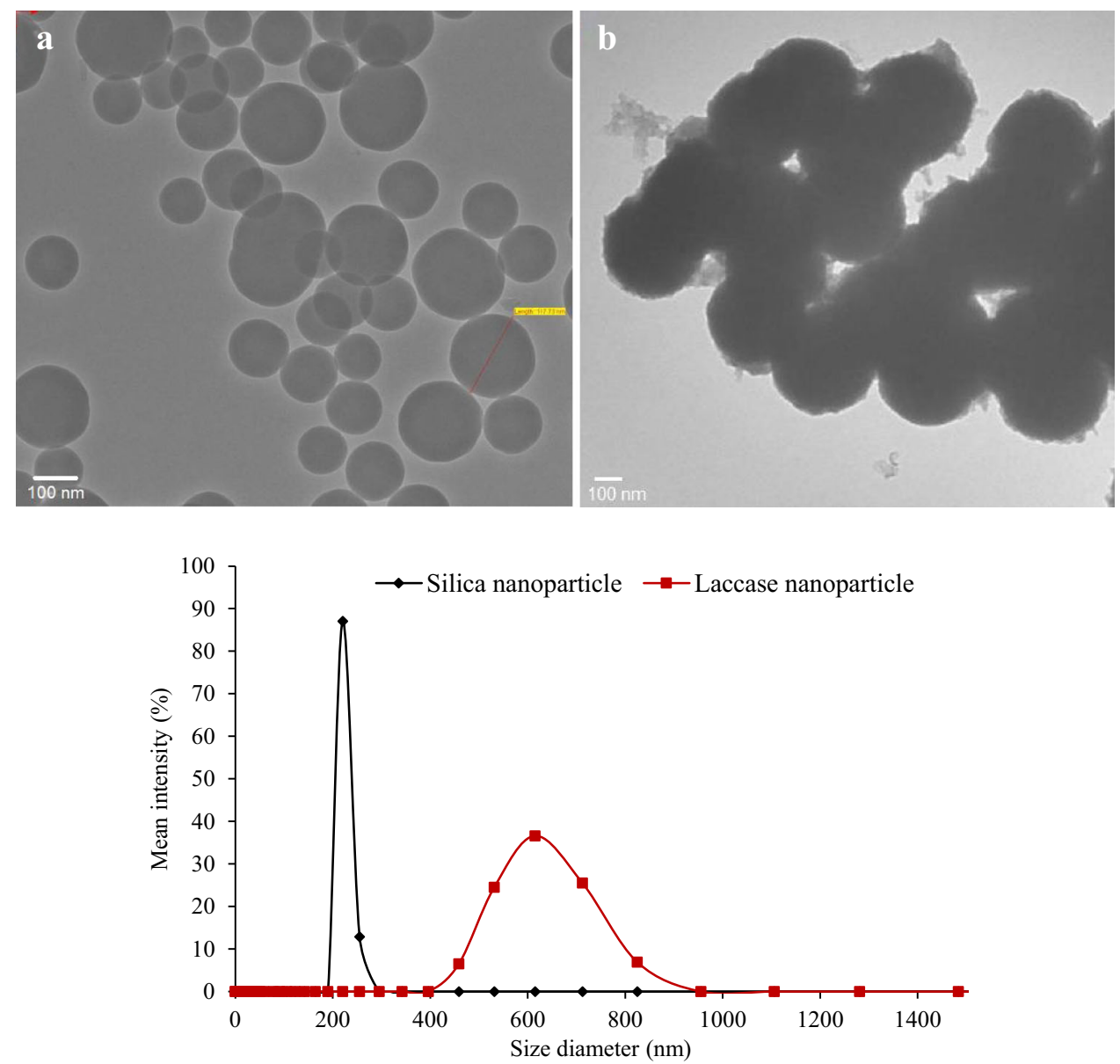

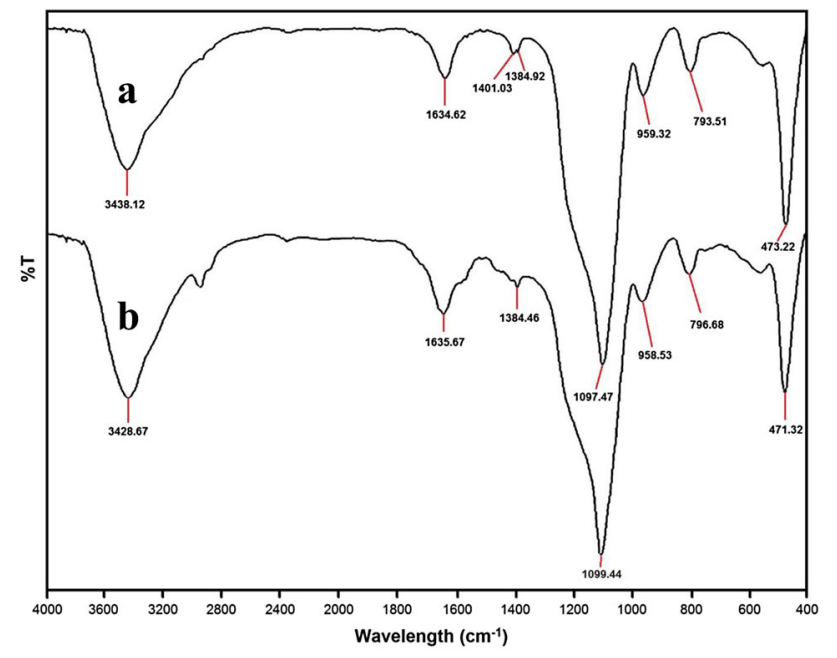

Fig. 3 Fourier transform IR spectrum of a nanosilica and b laccase nanoparticle

a comparable decrease in residual activity within the same $\mathrm{pH}$ range. Similarly, 0.5 and 1.5 unit shift of optimum $\mathrm{pH}$ after covalent immobilization of laccase on $\mathrm{Fe}_{3} \mathrm{O}_{4}$-CS-CCn and $\mathrm{Fe}_{3} \mathrm{O}_{4}$-CS-EDAC support, respectively [29]. Wang et al. [30] also reported a shift in optimum $\mathrm{pH}$ for the oxidation of catechol upon immobilization of laccase on magnetic mesoporous nanosilica.

\section{Temperature and $\mathrm{pH}$ stability}

Purified laccase and laccase nanoparticles presented 41 and $66 \%$ of residual activity at $40{ }^{\circ} \mathrm{C}$ after $24 \mathrm{~h}$, respectively (Fig. 5). The results showed that the cross-linking of laccase on nanosilica increased the stability by $25-30 \%$ in temperature range of $40-60{ }^{\circ} \mathrm{C}$. The initial activity of purified laccase was reduced up to $75 \%$ at $70{ }^{\circ} \mathrm{C}$ within $4 \mathrm{~h}$ of incubation, while laccase nanoparticle showed $73 \%$ of its initial activity. Purified laccase completely inactivated at $70{ }^{\circ} \mathrm{C}$ after $24 \mathrm{~h}$, while laccase nanoparticles retained $14 \%$ of initial activity. Higher temperature leads to the changes in the conformation and structure due to the breakage of bonds, thus, leading to decreased activity. The stability in laccase nanoparticles at higher temperature suggested that the exposed amine group on surface of laccase readily coupled with an aldehyde group in the nanoparticles to form a stable imine bond, which stabilizes the enzyme. When enzymes immobilized on support, materials create a kind of protection and provide a 

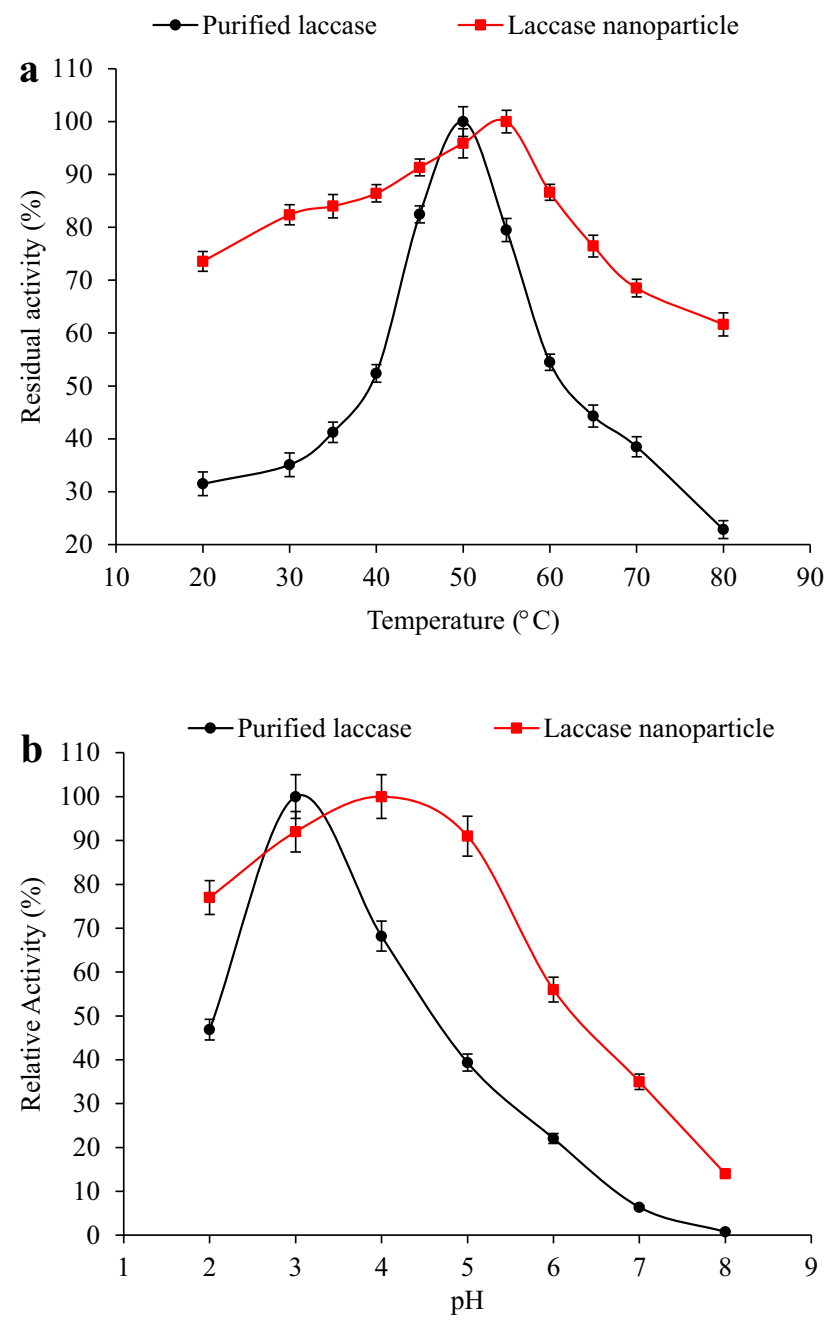

Fig. 4 Effect of temperature (a) and $\mathrm{pH}$ (b) on activity of purified laccase and laccase nanoparticle

resistance against the conformational changes of enzyme structure, which results in an increased thermal stability of laccase nano-conjugates [31]. Hu et al. [32] reported that laccase immobilized on nanoparticle and kaolinite was more stable as compared to the free laccase when laccase nano-conjugates incubated in a temperature range of $40-70{ }^{\circ} \mathrm{C}$.

Laccase nanoparticles depicted more than 55\% residual laccase activity at all tested $\mathrm{pH}$ values after $24 \mathrm{~h}$ of incubation, as shown in Fig. 6. Laccase nanoparticle exhibited $58 \%$ residual activity after $24 \mathrm{~h}$ of incubation at $\mathrm{pH} 3.0$, while purified laccase depicted only $28 \%$ residual activity at the same $\mathrm{pH}$. Laccase nanoparticle showed 5-10\% improvement in $\mathrm{pH}$ stability as compared to purified laccase at $\mathrm{pH} 4.0$ and 5.0. Improvement in $\mathrm{pH}$ stability might be observed due to the multipoint attachment of laccase on immobilization, nanosilica made laccase less prone to $\mathrm{pH}$ induced conformational changes. Similar results have been reported by several researchers that showed that the $\mathrm{pH}$ stability of laccase was improved within $\mathrm{pH}$ range of 2.0-7.0 after immobilization on DEAE-Granocel 500 and sol-gel matrix, respectively [25, 33].

\section{Storage stability of laccase nanoparticle}

To store catalyst for a long time period, storage stability is a major concern. Storage stability of purified laccase and laccase nanoparticle at storage temperature of 4 and $-20{ }^{\circ} \mathrm{C}$ are presented in Fig. $7 \mathrm{a}$ and b, respectively. The results depicted that laccase nanoparticle retained $82 \%$ of residual activity when it was stored at $4{ }^{\circ} \mathrm{C}$ for 60 days, while purified laccase retained only $44 \%$ of its initial activity. When storage temperature was $-20{ }^{\circ} \mathrm{C}$, residual activity of laccase nanoparticle and purified laccase was found to be $91 \%$ and $74 \%$, respectively, after 60 days. Results showed that laccase nanoparticle exhibited improved storage stability as compared to purified laccase. This might be occurred due to the stability in the active conformation of laccase by multipoint interactions with amino-functionalized nanosilica. Huang et al. [22] reported $85 \%$ residual activity of a $\mathrm{CuTAPc}-\mathrm{Fe}_{3} \mathrm{O}_{4}$ laccase nanoparticle as compared to the $30 \%$ residual activity of laccase after 30 days storage at $4{ }^{\circ} \mathrm{C}$. Bayramoglu et al. [26] reported $37 \%$ residual activity of laccase immobilized on CHX-g-p(IA)-Cu(II) membrane after 35 days of storage at $4{ }^{\circ} \mathrm{C}$ as compared to the complete loss of the activity of laccase.

\section{Reusability of laccase nanoparticle}

Laccase is an expensive biocatalyst; the reuse of catalyst makes the enzymatic process economically viable to cut down production cost. Results depicted that more than $87.6 \%$ of laccase activity was retained till 16th cycle. Thereafter, a gradual decrease in laccase activity was observed after each cycle and almost $79 \%$ of residual activity was retained till 20th cycle (Fig. 7c). Laccase cross-linked with nanosilica was reasonably stable when repeatedly used for catalysis of ABTS oxidation. This property of laccase nanoparticle is beneficial for the application in a batch or in a continuous mode. Bayramoglu et al. [26] reported $81 \%$ residual activity of laccase immobilized on CHX-g-p(IA)-Cu(II) membrane, after 10th cycle of syringaldazine oxidation. Liu et al. [34] reported $50 \%$ residual activity of laccase immobilized on CMMC support after 10th cycle of ABTS oxidation.

\section{Kinetic studies of laccase nanoparticle}

The kinetic parameters such as $K_{\mathrm{m}}$ and $V_{\max }$ vary considerably depending upon the types of enzymes, which support materials and process conditions. Lower $V_{\max }$ may 

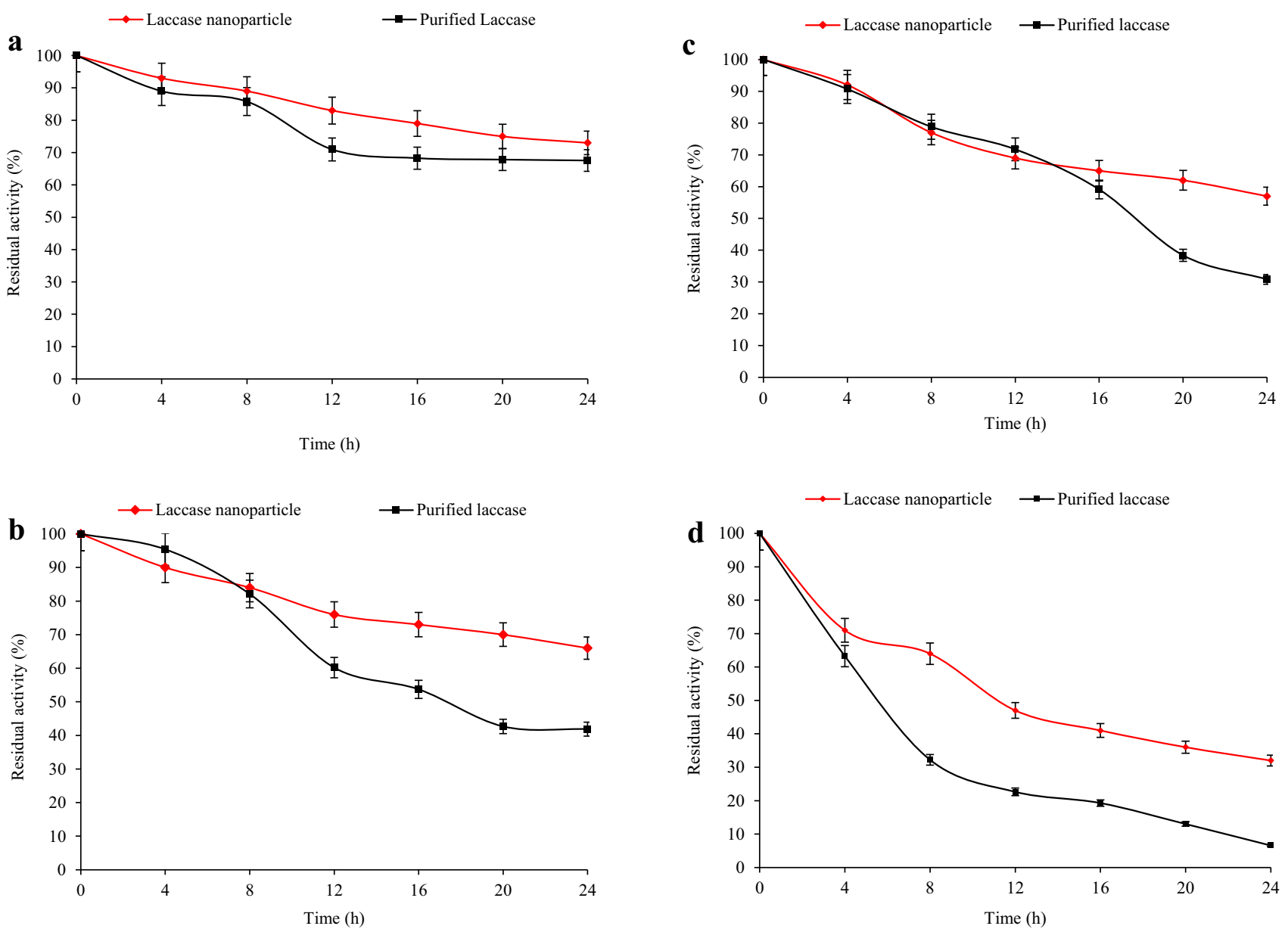

$\rightarrow$ Laccase nanoparticle $\rightarrow$ Purfied laccase

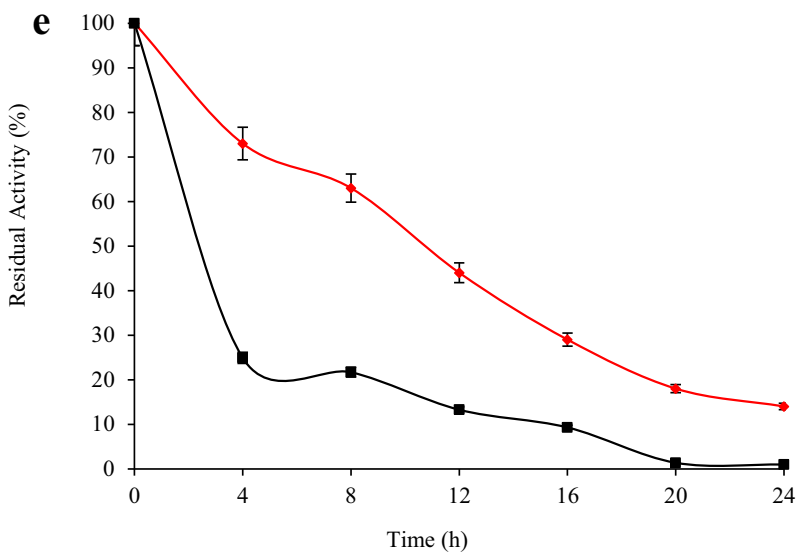

Fig. 5 Temperature stability of purified laccase and laccase nanoparticle at a $30{ }^{\circ} \mathrm{C}, \mathbf{b} 40{ }^{\circ} \mathrm{C}, \mathbf{c} 50{ }^{\circ} \mathrm{C}, \mathbf{d} 60{ }^{\circ} \mathrm{C}$, and e $70{ }^{\circ} \mathrm{C}$

have resulted from mass transfer limitations and reduction in enzyme-substrate affinities after immobilization. Reduction in $V_{\max }$ after laccase immobilization has also been reported by various researchers. The apparent $K_{\mathrm{m}}$ of immobilized laccase nanoparticles was found to be $0.5 \mathrm{mM}$ which was $21.05 \%$ higher than purified laccase $(0.19 \mathrm{mM})$.
$V_{\max }$ of laccase nanoparticle was found to be $3.58 \times 10^{2}$ $\mathrm{mM} / \mathrm{min}$, which is only $29.01 \%$ of $V_{\max }$ value of the purified laccase $\left(12.34 \times 10^{2} \mathrm{mM} / \mathrm{min}\right)$. The results depicted that the catalytic efficiency of laccase nanoparticle was lower than the purified laccase. The lower catalytic efficiency of laccase nanoparticle may be due to the rigid 

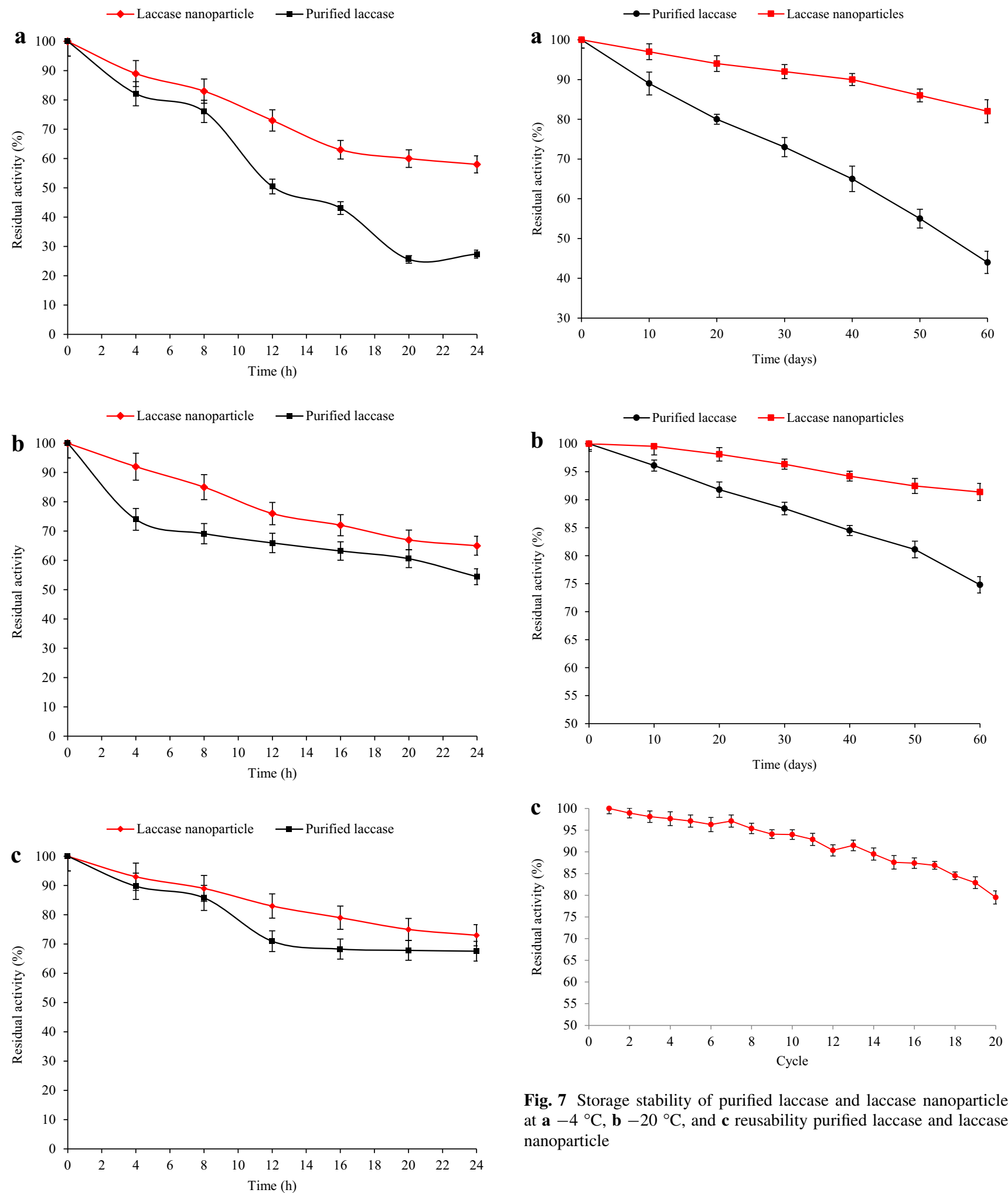

Fig. 7 Storage stability of purified laccase and laccase nanoparticle at $\mathbf{a}-4{ }^{\circ} \mathrm{C}, \mathbf{b}-20^{\circ} \mathrm{C}$, and $\mathbf{c}$ reusability purified laccase and laccase nanoparticle

Fig. $6 \mathrm{pH}$ stability purified laccase and laccase nanoparticle at a $\mathrm{pH}$ $3, \mathbf{b} \mathrm{pH} 4$, and $\mathbf{c} \mathrm{pH} 5$

conformation of enzyme in nanoparticle form, which will not allow any changes in the conformation of active site to accommodate the substrates. When enzyme cross-linked

with nanoparticle, neighbouring enzyme molecules sterically hinder the active centres of enzyme, so all enzyme molecules may not be available for the substrates, resulting the lower catalytic efficiency of enzyme. A lower catalytic efficiency of laccase crystal had been observed by Roy et al. [35] wherein $V_{\max }$ of CLEC laccase was only $12 \%$ 
than the $V_{\max }$ of native laccase. Huang et al. [22] also reported lower catalytic efficiency of CuTAPc- $\mathrm{Fe}_{3} \mathrm{O}_{4}$ nanoparticle laccase as compared to free laccase, who reported $88.88 \%$ higher $K_{\mathrm{m}}$ and $43.33 \%$ lower $V_{\max }$ value of CuTAPc- $\mathrm{Fe}_{3} \mathrm{O}_{4}$ nanoparticle laccase as compared to free laccase.

\section{Decolourization of RV 1 dye using laccase nanoparticle}

Incubation of RV 1 in the presence of purified laccase and immobilized silica laccase nanoparticles resulted in a detectable reduction in absorbance at $560 \mathrm{~nm}$. Laccase nanoparticles showed the $66 \%$ of decolourization of dye within $4 \mathrm{~h}$, while purified laccase presented $50 \%$ decolourization. Upon further incubation, $96.76 \%$ decolourization of RV 1 dye was achieved using laccase nanoparticles. The surface area of nanosilica greatly enhanced the catalytic efficiency of laccase, causing the higher decolourization of RV 1 dye (Fig. 8a). Valle-Vigón and Fuertes [36] reported $80 \%$ dye degradation of acid green 25 and remazol brilliant blue by magnetically separable carbon capsule loaded with laccase. Bayramoglu et al. [26] reported 48, 37, and 19\% decolourization of methyl orange, cibcron blue F3GA, and reactive black 5 dyes by Trametes versicolour laccase immobilized on CHX-g-p(IA)-Cu(II) membrane. Makas et al. [37] also reported 35\% decolourization of methyl orange dye after $6 \mathrm{~h}$ treatment with laccase entrapped in semi-IPNs prepared from k-carrageenan.

Laccase nanoparticle showed more than $75 \%$ decolourization of $\mathrm{RV} 1$ dye within a $\mathrm{pH}$ range of 3.0-6.0 (Fig. 8b). The optimum $\mathrm{pH}$ for dye decolourization was 4.0 wherein $96.85 \%$ of decolourization of RV 1 dye was obtained. However, decolourization of RV 1 dye was $31 \%$ at neutral ( $\mathrm{pH}$ 7.0). Usluoglu and Arabaci [38] reported $\mathrm{pH}$ 4.0 as an optimum $\mathrm{pH}$ for maximum decolourization of acid and metal complex dyes by phenol oxidase immobilized on to alginate beads. Mogharabi et al. [39] reported $\mathrm{pH} 8.0$ as optimum $\mathrm{pH}$ for the decolourization of dye solution of various textile dyes by laccase immobilized on alginate gelatin gel.

The optimum temperature for maximum decolourization (96.78\%) of RV 1 by laccase nanoparticle was $30^{\circ} \mathrm{C}$ (Fig. 8c). Decolourization of RV 1 by laccase nanoparticle was also comparable to the incubation temperature range from 25 to $50{ }^{\circ} \mathrm{C}$. However, further increase in temperature results in the decreased decolourization of RV 1 . The decrease in decolourization might be observed due to the unfolding or degradation of laccase at high temperature. Similar results have been observed by Mogharabi et al. [39] for the decolourization of crystal violet dye by laccase in alginate-gelatin mixed gel.
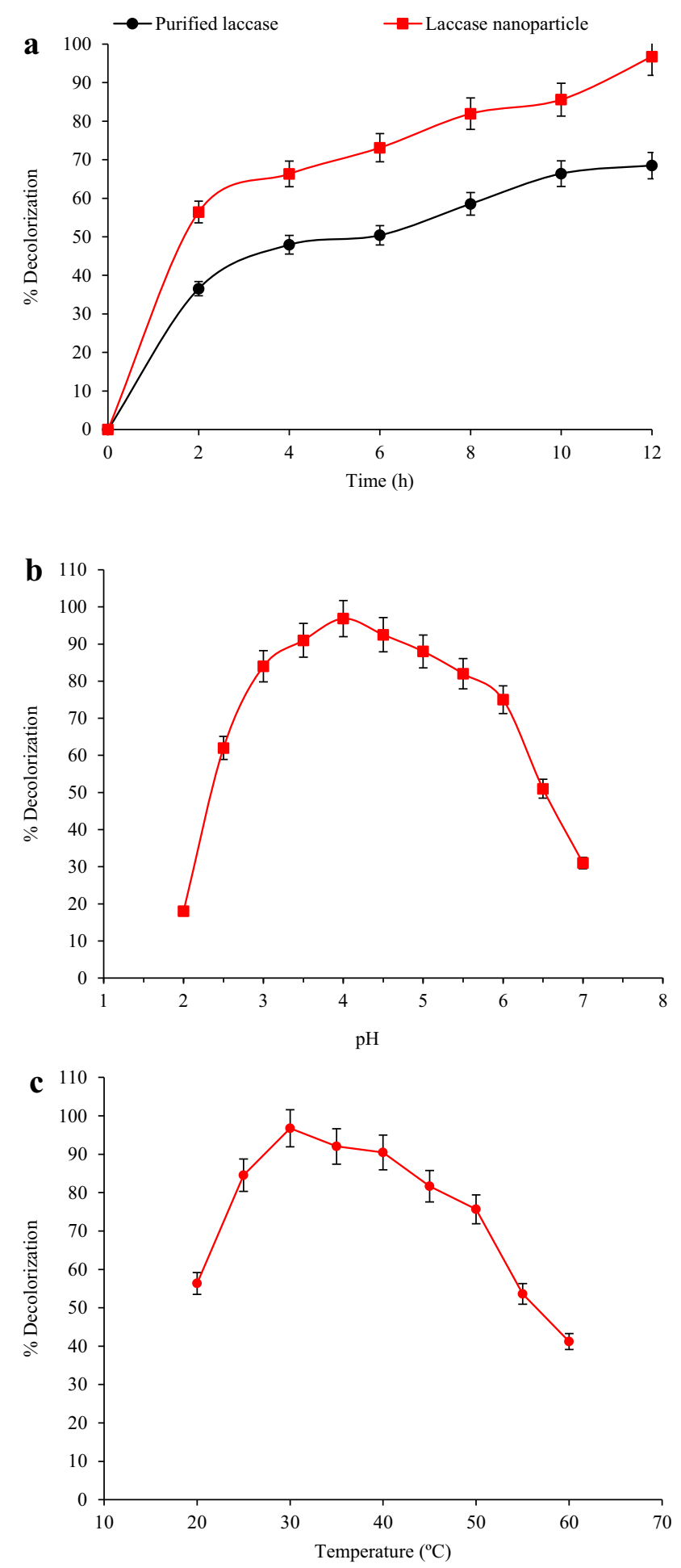

Fig. 8 Purified laccase and laccase nanoparticles were used for a decolorization of $\mathrm{RV} \mathrm{1,} \mathrm{pH}$ (b) and temperature (c) effects were checked on the decolorization of RV 1

\section{Analysis of degraded metabolites}

The chromatogram of control dye depicted a single $R_{f}$ value (0.93), while degraded metabolites showed the four 
$\mathrm{R}_{\mathrm{f}}$ value $(0.90,0.85,0.73$, and 0.27$)$. Disappearance of the band of control dye suggested that laccase nanoparticles efficiently degraded RV 1 dye and formed different metabolites which contained four different $R_{\mathrm{f}}$ values. The data of GC-MS analysis revealed the presence of several peaks which correspond to the presence of compounds produced after degradation RV 1 dye. Two oxidative cleavage (1 and 2) sites and proposed pathway of degradation of RV 1 is illustrated in Fig. 9. The initial oxidative cleavage of azo bonds from parent dye was resulted into three low-molecular-weight products. These compounds were sodium-3-chloro-4, 5-dihydroxybenzene sulfonate $(\mathrm{m} / \mathrm{z} ;$ 246), sodium-4-amino-5-hydroxyl-naphthalene-2, 7-disulfonate $(\mathrm{m} / \mathrm{z} ; 364)$, and sodium-3-(4-chloro-1, 3, 5-triazine-2-ylamine) benzene sulfonate $(\mathrm{m} / \mathrm{z} ; 306)$. Subsequent oxidation of sodium-3-(4-chloro-1, 3, 5 triazine-2ylamine) benzene sulfonate resulted into two compounds which were sodium 3- amino-4-hydroxyl benzene sulfonate $(\mathrm{m} / \mathrm{z} ; 207)$ and 4-chloro-1, 3, 5-triazine-2-ol $(\mathrm{m} / \mathrm{z} ; 135)$ formation. Thus, analytical studies revealed RV 1 degradation yielded low-molecular-weight compounds using oxidative mechanism of laccase nanoparticles. Similar results were reported by Zille et al. [40], who studied degradation pathway of azo dyes, 3-(4-dimethylamino-1phenylazo) benzenesulfonic acid (dye I) and 3-(2-hydroxy1-naphthylazo) benzenesulfonic acid (dye II) using Trametes villosa laccase.

\section{Toxicity analysis of degraded metabolites}

In general, treated/untreated effluent of dyes directly releases to the environment, so it shows the toxicity towards plants, animals, and microbes. Among them, microbes and plants have been used for decades as a biosensor for the toxicity of environmental pollutants [28, 41]. Evaluating the microbial toxicity of RV 1 dye on agricultural important micro-organisms like $R$. radiobacter and Azotobacter sp. showed inhibition zone $10.5 \pm 0.8$ and $12.4 \pm 0.5 \mathrm{~mm}$, respectively. Degraded metabolites did not show inhibition zone against these bacteria. B. subtilis $(15.9 \pm 0.9 \mathrm{~mm}), S$. aureus $(15.2 \pm 1.0 \mathrm{~mm}), S$. typhi $(15.1 \pm 1.2 \mathrm{~mm})$, and E. coli $(14.3 \pm 0.8 \mathrm{~mm})$ were also significantly inhibited by RV1 dye. In contrast, degraded metabolites exhibited less zone of inhibition in case of $B$. subtilis $(7.8 \pm 1.0 \mathrm{~mm})$, E. coli $(8.1 \pm 0.9 \mathrm{~mm})$, and $S$. typhi $(10.2 \pm 0.8 \mathrm{~mm})$, while $S$. aureus $(12.9 \pm 1.4 \mathrm{~mm})$

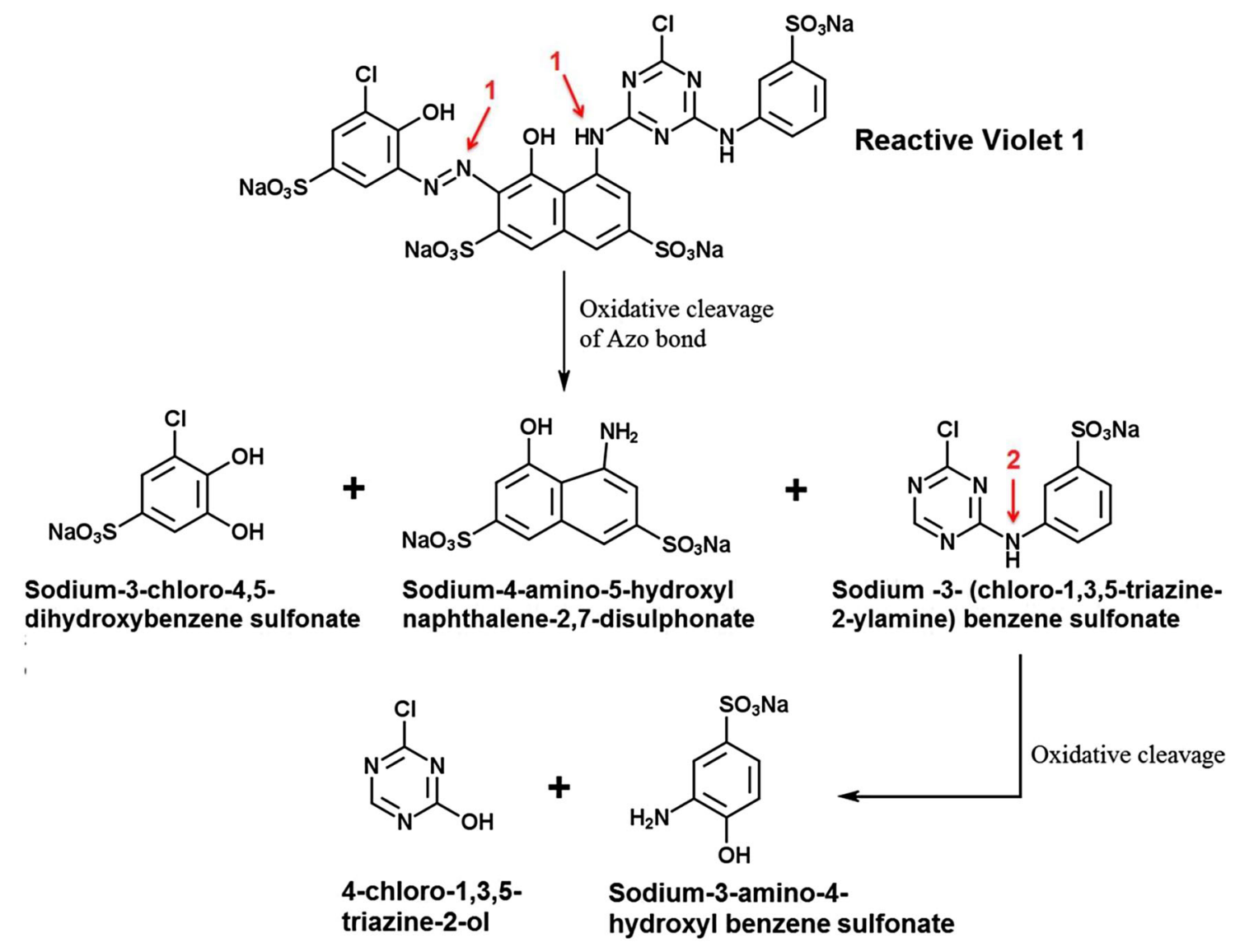

Fig. 9 Proposed degradation pathway for RV 1 dye by laccase nanoparticles 


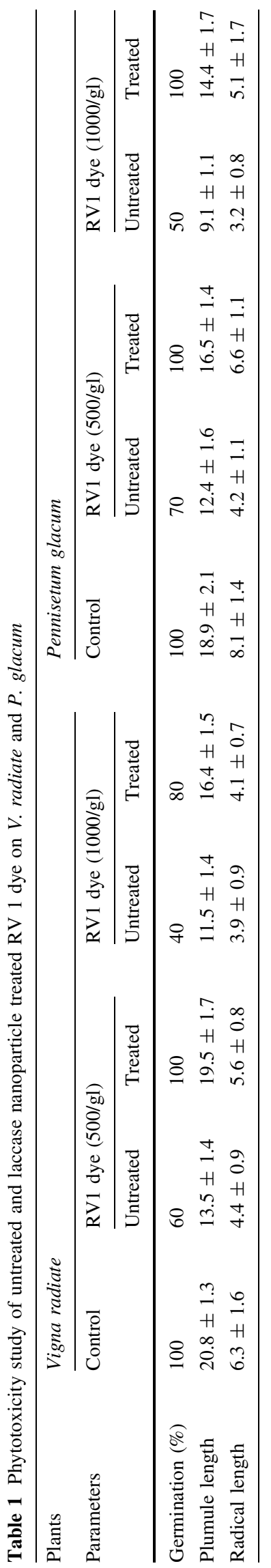

depicted almost similar inhibition zone. Growth of $B$. cereus and Azotobacter sp. was unaffected when both bacteria were tested against degraded metabolites of Synozol red HF-6BN using Aspergillus niger and $\mathrm{Ni}$ grospora sp. [42].

Vigna radiata seeds were treated with 500 and $1000 \mathrm{mg} / \mathrm{l}$ concentration of RV 1 dye, the germination rate was 90 and $40 \%$, respectively. In contrast, treatment with degraded products of the same concentration had a minor effect on plants, as germination rates were 100 and $80 \%$, plumule lengths were $19.5 \pm 1.7$ and $16.4 \pm 1.5 \mathrm{~cm}$, and radical lengths were found to be $5.6 \pm 0.8$ and $4.1 \pm 0.7 \mathrm{~cm}$, respectively. Treatment of Pennisetum glacum seeds with RV 1 dye (500 and $1000 \mathrm{mg} / \mathrm{l})$ resulted in lower germination (80 and 50\%, respectively) in plant seeds (Table 1). Seed germination of degraded metabolites depicted the lower inhibition than control dye samples, suggesting the non-toxic nature of degraded metabolites. Non-toxic nature of degraded metabolite of Rubine GFL dye sample and textile effluents was observed for germination of $S$. vulgare and $P$. mungo seeds as compared to original dye and textile effluent samples [43].

\section{Conclusions}

Overall, amino-functionalized nanosilica was synthesized chemically and anchored covalently using glutaraldehyde to laccase enzyme. Due to the immobilization with nanosilica, laccase nanoparticles obtained higher efficiency at higher $\mathrm{pH}$ and temperature compared to purified laccase. Laccase nanoparticles displayed higher stability with repeated use, long-term storage, and thermal stability than purified laccase. Furthermore, prepared nano-conjugates efficiently cleaved RV 1 dye and transformed into lesstoxic products, which represented an additional advantage for waste water treatment. Though laccase nanoparticles obtained lower catalytic efficiency than purified laccase, laccase nanoparticles are promising biocatalysts that can be used for the elimination of synthetic dyes.

Acknowledgements The authors are very obliged to the Department of Biotechnology (DBT Sanction No. BT/PR9134/BCE/08/543/2007) and Ministry of Science and Technology, New Delhi, for their financial support. The authors also wish to acknowledge SICART, V.V. Nagar, Gujarat, for providing the necessary instrumentation facilities.

Open Access This article is distributed under the terms of the Creative Commons Attribution 4.0 International License (http://crea tivecommons.org/licenses/by/4.0/), which permits unrestricted use, distribution, and reproduction in any medium, provided you give appropriate credit to the original author(s) and the source, provide a link to the Creative Commons license, and indicate if changes were made. 


\section{References}

1. Rao, M., Scelza, R., Acevedo, F., Diez, M., Gianfreda, L.: Enzymes as useful tools for environmental purposes. Chemosphere 107, 145-162 (2014)

2. Avvakumova, S., Colombo, M., Tortora, P., Prosperi, D.: Biotechnological approaches toward nanoparticle biofunctionalization. Trends Biotechnol. 32, 11-20 (2014)

3. Mukhopadhyay, A., Dasgupta, A.K., Chakrabarti, K.: Enhanced functionality and stabilization of a cold active laccase using nanotechnology based activation-immobilization. Bioresour. Technol. 179, 573-584 (2015)

4. Lettera, V., Pezzella, C., Cicatiello, P., Piscitelli, A., Giacobelli, V.G., Galano, E., Amoresano, A., Sannia, G.: Efficient immobilization of a fungal laccase and its exploitation in fruit juice clarification. Food Chem. 196, 1272-1278 (2016)

5. Cipolatti, E.P., Silva, M.J.A., Klein, M., Feddern, V., Feltes, M.M.C., Oliveira, J.V., Ninow, J.L., de Oliveira, D.: Current status and trends in enzymatic nanoimmobilization. J. Mol. Catal. B Enzym. 99, 56-67 (2014)

6. da Costa, J.P., Oliveira-Silva, R., Daniel-da-Silva, A.L., Vitorino, R.: Bionanoconjugation for proteomics applications-an overview. Biotechnol. Adv. 32, 952-970 (2014)

7. Min, K., Yoo, Y.J.: Recent progress in nanobiocatalysis for enzyme immobilization and its application. Biotechnol. Bioproc. E. 19, 553-567 (2014)

8. Yang, H.W., Hua, M.Y., Chen, S.L., Tsai, R.Y.: Reusable sensor based on high magnetization carboxyl-modified graphene oxide with intrinsic hydrogen peroxide catalytic activity for hydrogen peroxide and glucose detection. Biosens. Bioelectron. 41, 172-179 (2013)

9. Hou, J., Dong, G., Ye, Y., Chen, V.: Laccase immobilization on titania nanoparticles and titania-functionalized membranes. J. Membr. Sci. 452, 229-240 (2014)

10. Ding, S., Cargill, A.A., Medintz, I.L., Claussen, J.C.: Increasing the activity of immobilized enzymes with nanoparticle conjugation. Curr. Opin. Biotechol. 34, 242-250 (2015)

11. Kües, U.: Fungal enzymes for environmental management. Curr. Opin. Biotechol. 33, 268-278 (2015)

12. Senthivelan, T., Kanagaraj, J., Panda, R.: Recent trends in fungal laccase for various industrial applications: an ecofriendly approach-A review. Biotechnol. Bioproc. E. 21, 19-38 (2016)

13. Asif, M.B., Hai, F.I., Singh, L., Price, W.E., Nghiem, L.D.: Degradation of pharmaceuticals and personal care products by white-rot fungi-a critical review. Curr. Pollut. Rep. 3(2), 88-103 (2017)

14. Fernández-Fernández, M., Sanromán, M.Á., Moldes, D.: Recent developments and applications of immobilized laccase. Biotechnol. Adv. 31, 1808-1825 (2013)

15. Catherine, H., Penninckx, M., Frédéric, D.: Product formation from phenolic compounds removal by laccases: a review. Environ. Technol. Innov. 5, 250-266 (2016)

16. Pang, R., Li, M., Zhang, C.: Degradation of phenolic compounds by laccase immobilized on carbon nanomaterials: diffusional limitation investigation. Talanta 131, 38-45 (2015)

17. Richter, M., Schulenburg, C., Jankowska, D., Heck, T., Faccio, G.: Novel materials through nature's catalysts. Mater. Today 18, 459-467 (2015)

18. Li, Q.Y., Wang, P.Y., Zhou, Y.L., Nie, Z.R., Wei, Q.: A magnetic mesoporous $\mathrm{SiO}_{2} / \mathrm{Fe}_{3} \mathrm{O}_{4}$ hollow microsphere with a novel network-like composite shell: synthesis and application on laccase immobilization. J. Sol Gel Sci. Technol. 78, 523-530 (2016)

19. Asther, M., Lesage, L., Drapron, R., Corrieu, G., Odier, E.: Phospholipid and fatty acid enrichment of Phanerochaete chrysosporium INA-12 in relation to ligninase production. Appl. Microbiol. Biot. 27, 393-398 (1988)

20. Rudakiya, D.M., Gupte, A.: Degradation of hardwoods by treatment of white rot fungi and its pyrolysis kinetics studies. Int. Biodeter. Biodegr. 120, 21-35 (2017)

21. Stöber, W., Fink, A., Bohn, E.: Controlled growth of monodisperse silica spheres in the micron size range. J. Colloid Interface Sci. 26, 62-69 (1968)

22. Huang, J., Xiao, H., Li, B., Wang, J., Jiang, D.: Immobilization of Pycnoporus sanguineus laccase on copper tetra-aminophthalocyanine-Fe3O4 nanoparticle composite. Biotechnol. Appl. Bioc. 44, 93-100 (2006)

23. Lowry, O.H., Rosebrough, N.J., Farr, A.L., Randall, R.J.: Protein measurement with the Folin phenol reagent. J. Biol. Chem. 193, 265-275 (1951)

24. Kalme, S., Jadhav, S., Parshetti, G., Govindwar, S.: Biodegradation of Green HE4B: co-substrate effect, biotransformation enzymes and metabolite toxicity analysis. Indian J. Microbiol. 50, 156-164 (2010)

25. Al-Adhami, A.J., Bryjak, J., Greb-Markiewicz, B., PeczyńskaCzoch, W.: Immobilization of wood-rotting fungi laccases on modified cellulose and acrylic carriers. Process Biochem. 37, 1387-1394 (2002)

26. Bayramoglu, G., Gursel, I., Yilmaz, M., Arica, M.Y.: Immobilization of laccase on itaconic acid grafted and $\mathrm{Cu}$ (II) ion chelated chitosan membrane for bioremediation of hazardous materials. J. Chem. Technol. Biot. 87, 530-539 (2012)

27. Beganskiene, A., Sirutkaitis, V., Kurtinaitienè, M., Juškènas, R., Kareiva, A.: FTIR, TEM and NMR investigations of Stöber silica nanoparticles. Mater. Sci. 10, 287-290 (2004)

28. Rudakiya, D.M., Pawar, K.: Bactericidal potential of silver nanoparticles synthesized using cell-free extract of Comamonas acidovorans: in vitro and in silico approaches. 3 Biotech 7(2), 92 (2017)

29. Kalkan, N.A., Aksoy, S., Aksoy, E.A., Hasirci, N.: Preparation of chitosan-coated magnetite nanoparticles and application for immobilization of laccase. J. Appl. Polym. Sci. 123, 707-716 (2012)

30. Wang, F., Guo, C., Yang, L.R., Liu, C.Z.: Magnetic mesoporous silica nanoparticles: fabrication and their laccase immobilization performance. Bioresour. Technol. 101, 8931-8935 (2010)

31. Cabana, H., Ahamed, A., Leduc, R.: Conjugation of laccase from the white rot fungus Trametes versicolour to chitosan and its utilization for the elimination of triclosan. Bioresour. Technol. 102, 1656-1662 (2011)

32. Hu, X., Zhao, X., Hwang, H.M.: Comparative study of immobilized Trametes versicolour laccase on nanoparticles and kaolinite. Chemosphere 66, 1618-1626 (2007)

33. Irshad, M., Bahadur, B.A., Anwar, Z., Yaqoob, M., Ijaz, A., Iqbal, H.M.N.: Decolorization applicability of sol-gel matriximmobilized laccase produced from Ganoderma leucidum using agro-industrial waste. BioResources 7, 4249-4261 (2012)

34. Liu, Y., Zeng, Z., Zeng, G., Tang, L., Pang, Y., Li, Z., Liu, C., Lei, X., Wu, M., Ren, P.: Immobilization of laccase on magnetic bimodal mesoporous carbon and the application in the removal of phenolic compounds. Bioresour. Technol. 115, 21-26 (2012)

35. Roy, J.J., Abraham, T.E., Abhijith, K., Kumar, P.S., Thakur, M.: Biosensor for the determination of phenols based on cross-linked enzyme crystals (CLEC) of laccase. Biosens. Bioelectron. 21, 206-211 (2005)

36. Valle-Vigón, P., Fuertes, A.B.: Magnetically separable carbon capsules loaded with laccase and their application to dye degradation. RSC Adv. 1, 1756-1762 (2011)

37. Makas, Y.G., Kalkan, N.A., Aksoy, S., Altinok, H., Hasirci, N.: Immobilization of laccase in $\kappa$-carrageenan based semi- 
interpenetrating polymer networks. J. Biotechnol. 148, 216-220 (2010)

38. Usluoglu, A., Arabaci, G.: Dye decolourization by Dandelion (Taraxacum officinale) polyphenol oxidase immobilized into alginate beads. Res. J. Chem. Environ. 17, 16-20 (2013)

39. Mogharabi, M., Nassiri-Koopaei, N., Bozorgi-Koushalshahi, M., Nafissi-Varcheh, N., Bagherzadeh, G., Faramarzi, M.A.: Immobilization of laccase in alginate-gelatin mixed gel and decolourization of synthetic dyes. Bioinorg. Chem. Appl. 1-6 (2012). doi:10.1155/2012/823830

40. Zille, A., Górnacka, B., Rehorek, A., Cavaco-Paulo, A.: Degradation of azo dyes by Trametes villosa laccase over long periods of oxidative conditions. Appl. Environ. Microb. 71, 6711-6718 (2005)
41. Jadhav, S.B., Phugare, S.S., Patil, P.S., Jadhav, J.P.: Biochemical degradation pathway of textile dye Remazol red and subsequent toxicological evaluation by cytotoxicity, genotoxicity and oxidative stress studies. Int. Biodeter. Biodegr. 65, 733-743 (2011)

42. Ilyas, S., Rehman, A.: Decolourization and detoxification of Synozol red HF-6BN azo dye, by Aspergillus niger and $\mathrm{Ni}$ grospora sp. Iran J. Environ. Health Sci Eng. 10(1), 12 (2013)

43. Lade, H.S., Waghmode, T.R., Kadam, A.A., Govindwar, S.P.: Enhanced biodegradation and detoxification of disperse azo dye Rubine GFL and textile industry effluent by defined fungalbacterial consortium. Int. Biodeter. Biodegr. 72, 94-107 (2012) 